\title{
La Psicología a Contraluz: Debate Epistemológico y Estatus Disciplinar
}

\section{Psychology in the Light: An Epistemological and Disciplinary Status Debate}

\author{
Mario Villalobos Kirmayr \\ Universidad Santo Tomás de Chile
}

(Recepción: Abril 2003 - Aceptación: Julio 2003)

\begin{abstract}
A través de nociones epistemológicas clásicas como falsación, paradigma y ciencia normal, se examina el estatus científico de la disciplina psicológica tanto en sus niveles de lógica investigativa como de desarrollo institucional. Asimismo, bajo la noción de determinismo estructural maturaniana, se analiza la posibilidad de entender lo mental como objeto de estudio científico.

El examen muestra las dificultades de enmarcar a la psicología dentro del campo de las ciencias, sea por la lógica no falsacionista de su investigación, por el carácter preparadigmático de su institucionalidad, o por la imposibilidad de constituir su objeto de estudio como una unidad con determinación estructural.

Palabras clave: Demarcación científica, paradigma, determinismo estructural.
\end{abstract}

\begin{abstract}
Through classic epistemological notions, such as falsification, paradigm, and traditional science, the scientific status of the psychological discipline is examined as much in its levels of investigative logic as in those of institutional development. At the same time, under Maturana's notion of structural determinism, the possibility of understanding the mental as an object or scientific study is analyzed.

The test shown the difficulties of placing Psychology within a field of sciences; be it for the non-falsifying logic of its investigation, the pre-paradigmatic character of its institutionalism, or for the impossibility of constructing its objective of study as a unit with structural determination.
\end{abstract}

Key words: Scientific demarcation, paradigm, structural determinism.

\section{Introducción}

Las implicancias que el debate epistemológico pasado y actual pueda tener para el presente y futuro de la disciplina psicológica, es una cuestión que pocas veces se oye discutir al interior de la disciplina misma, y que queda más bien como tema de reflexión para filósofos y epistemólogos, salvando las excepciones de figuras como Watzlawick, Von Graserfeld, Piaget, y otros. No obstante dicha despreocupación, y más allá o más acá de cualquier discusión epistemológica, sabemos que tradicionalmente la psicología se ha enmarcado a sí misma dentro de las así llamadas disciplinas científicas; por de pronto, entendiendo por éstas el conjunto de tradiciones de conocimiento que tienen como

Psicólogo, Licenciado en Psicología, Pontificia U. Católica de Chile.

Correspondencia: Mario Villalobos K. Escuela de Psicología, Universidad Santo Tomás de Chile. Avda. Ejército Libertador 146, Santiago-Chile. (56-2) 632 4888,

E-mail: mariovilobos@hotmail.com criterio de demarcación un modo exclusivo y particular de validación, a saber, la validación científica. Si la demarcación provisoria dada para las ciencias incomoda por su apariencia tautológica, consideraré aquello como un buen comienzo para el siguiente debate, pues veremos prontamente que la univocidad para demarcar lo científico, y por extensión lo científicamente psicológico, dista mucho de ser un anhelo siquiera medianamente alcanzable.

Si tomamos a la psicología en conjunto y la sometemos a sólo algunos de los distintos análisis epistemológicos que se han llevado a cabo en esta extensa tradición de debate, podemos obtener como resultado una suerte de informe o perfil disciplinar parcial y tentativo, que pese a su carácter preliminar, nos puede aportar una visión diferente y complementaria a -aunque no necesariamente armónica o congruente con- la que nosotros hacedores de la psicología solemos tener.

Para ello me centraré en tres aproximaciones epistemológicas que tienen orígenes, discur- 


\section{VILLALOBOS}

sos, y áreas de reflexión distintos y variados. Esto para guardarnos de no extender el examen hacia dimensiones que excedan el alcance preliminar del presente trabajo, así como también para poder al menos triangular el análisis y no quedarnos -como se diría en el sentido popular médico- con una sola opinión.

Pero el ejercicio que se pretende no es tan sólo el de pasar revista a, a la manera como se mapea un área o zona del saber, sino más bien el de incomodar o perturbar a la disciplina psicológica para que ésta se muestre no como un paciente que se deja examinar, sino como un organismo vivo capaz de reacción y defensa, un ente que en el despliegue de sus fuerzas defensivas y de ataque, se nos muestre más vivo, auténtico y genuino. Es por esto que la estrategia inicial será deliberadamente impugnar la disciplina a través del hostigamiento que las distintas categorías epistemológicas puedan surtir sobre su epidermis, para luego ver, si tenemos suerte, la respectiva anafilaxis como respuesta defensiva. Asumiré por tanto en este ejercicio el rol provocativo, el del consabido tábano, y esperaremos por parte de quienes estimen oportuno acusar en sus mejillas el trazo del guante alzado, el rol de la legítima defensa y contraataque, si lo hubiere.

En primera instancia tomaremos las nociones popperianas de demarcación científica para examinar la disciplina psicológica en tanto actividad investigativa y productora de conocimiento. La lógica de la investigación científica propuesta por Popper será tomada como criterio de prueba para examinar si acaso el conocimiento producido por la disciplina psicológica cuenta o no como conocimiento científico. Puesto que el ejercicio está volcado a la examinación de la disciplina y no a la revisión de los debates epistemológicos per se, el autor en cuestión será recogido sólo en aquellos aspectos que resulten útiles para nuestra empresa, en desmedro de otras aportaciones tanto o más interesantes pero menos pertinentes a la hora de revisar el estatuto científico de la psicología.

En segundo lugar pondremos la disciplina psicológica a contraluz de algunas de las categorías epistemológicas elaboradas por Thomas Kuhn, donde el análisis del estatus científico se desplaza visiblemente hacia una revisión sociohistórica de las comunidades científicas, más allá del análisis de la lógica interna de la producción de conocimiento. También aquí, el propósito no será revisar en detalle las conceptualizaciones del autor, sino más bien atrapar en el aire de las disquisiciones lanzadas al debate epistemológico, aquellas categorías que nos sean útiles para alumbrar la anatomía y esqueleto de la psicología actual.

En tercer y último lugar acometeré un análisis de la disciplina psicológica, tomando como base la epistemología biológica en su vertiente más radical, a saber, aquella elaborada por la escuela chilena de Maturana y Varela. Esta elección se debe a que si bien en Piaget tenemos también un trabajo epistemológico estructural evolutivo, su constructivismo es más bien moderado (blando), toda vez que las nociones de esquemas cognitivos pese a su carácter diacrónico siguen señalando un aparato mental interno, razón por la cual el modelo no logra desprenderse del todo del marco dualista cartesiano. Y puesto que la táctica anunciada es la provocación, requerimos acá de material suficientemente corrosivo como para generar una reacción visible, requerimiento para el cual una noción constructivista débil como la de Piaget no califica.

Dicho todo esto, invitamos entonces a la psicología a pasar por las respectivas examinaciones.

\section{Sala $N^{\circ} 1$ : Popper y el falsacionismo}

Si nos ceñimos a la propuesta popperiana de demarcación científica, tendríamos que reconocer en la psicología un cumplimiento sólo parcial del criterio de cientificidad. Parcial no por una cuestión de grado, sino por la presencia simultánea dentro de un mismo cajón, de 'buenas y malas manzanas'. Como es sabido la empresa popperiana consiste en el esclarecimiento de una efectiva demarcación científica, cuyo propósito central es "...encontrar un criterio que nos permita distinguir entre las ciencias empíricas, por un lado, y los sistemas 'metafísicos', por otro" (Popper, 1962, p. 34). ${ }^{1}$ Ahora bien, por la palabra 'empírico' no se está entendiendo el que los enunciados de una teoría estén fundados o se originen a partir de la observación del mundo,

1 Debemos recordar que Popper pretende demarcar ciencia y no ciencia, pero no homologar no ciencia con sinsentidos (o absurdos). Este último camino, basado en un criterio positivista de significatividad lingüística, fue el exigido, en su momento, por los filósofos del Círculo de Viena. 


\section{LA PSICOLOGÍA A CONTRALUZ}

como se podría encontrar en cualquier enfoque empirista de la ciencia, sino más bien que éstos sean susceptibles de someter a pruebas de contrastación. Es decir, lo empírico está invocado no como fuente sino como destino, hecho que como veremos tendrá consecuencias para los intentos de cientificidad en psicología.

Como el mismo Popper se encargara de denunciar, habrían en psicología cuerpos teóricos completos, de amplia difusión y aplicación técnica, que no caerían dentro del rango de ciencia. En especial, Popper (1967) denunció en psicología el psicoanálisis como una práctica no científica, y en sociología el marxismo. Ambos serían sistemas interpretativos a toda prueba, es decir, sistemas de hipótesis explicativas que, aunque coherentes entre sí, no son susceptibles de someter a contrastación empírica. Tanto el psicoanálisis como el marxismo se comportarían como cuerpos teóricos capaces de absorber cualquier contraevidencia que les saliera al paso, reacomodando sus categorías conceptuales constantemente sin que éstas puedan nunca ser derribadas ni puestas en riesgo. Actitud dogmática que Popper calificó como "sesgo convencionalista" (1967, p. 62). Justamente por ser capaces de explicarlo todo, dichas teorías no constituirían sistemas científicos de explicación.

Lo que está en juego para dar carta de cientificidad a una teoría no es que sus hipótesis surjan o no de la observación acuciosa de los datos, pues de la mera observación de los hechos no es lógicamente lícito la inducción de leyes científicas. La verificación de los enunciados no es el criterio propuesto para las ciencias, pues "las teorías no son nunca verificables empíricamente" (Popper, 1962, p. 39). El criterio de selección para una teoría cualquiera ha de ser negativo en el sentido de que no se debe buscar cómo verificarla sino cómo refutarla. Los enunciados metafísicos deben ser descartados del ámbito científico no por carecer de sentido o estar desprovistos de significado -como era la tesis de Carnap-sino por no ser susceptibles de someter a contrastación empírica.

Aunque Popper invierte la tesis verificacionista del Círculo de Viena y plantea la asimetría entre verificación y falsación, en última instancia sigue siendo el choque con la empiria lo que determina la validez o no de las teorías en cuestión. El aparataje metodológico para llevar las hipótesis a falsación requerirá de todos modos operacionalizar los términos de la teoría, seña- lando claramente sus condiciones de observación y registro protocolar. Pero veremos ya que la mera operacionalización no es garante de cientificidad.

Lo que nos ocupa acá es la revisión del estatus de la disciplina psicológica, aquella que tiene como campo de escrutinio el mundo de lo mental, de lo psíquico. Un mundo que Popper, dentro de su terminología de los mundos, ve como intermediario entre el mundo físico (Mundo 1) y el de los productos objetivados de la mente humana (Mundo 3). El Mundo 2 del pensamiento subjetivo, aquél que "...la mayoría de los psicólogos (excepto los conductistas) tratan de describir, sin mucho éxito, mediante lo que no es más que un montón de metáforas tomadas del lenguaje de la física, la biología y la vida social" (Popper, 1967, p. 262), como tal no es de interés para el ejercicio epistemológico, pues del examen psicológico de cómo opera un científico podemos obtener material tan sólo para el anecdotario, pero en ningún caso para el esclarecimiento de la lógica científica. Claro está que para Popper la psicología en su conjunto no pasa de ser un discurso metafísico o a lo más pseudocientífico. Pero hay señalada en esta cita una excepción para el conductismo. ¿Significa esto que sólo dicho enfoque queda rescatado como verdaderamente científico? Veamos.

Dentro de la literatura psicológica, son prototípicos los casos del psicoanálisis y de los enfoques humanistas como ejemplos de no cientificidad, así como a su vez y a la contra, el conductismo radical lo es de cientificidad. Esta tradicional distinción y caracterización de los grandes enfoques psicológicos (que puede encontrarse en cualquiera de los manuales introductorios de psicología), señala que justamente uno de los aportes más significativos del conductismo es haber introducido el método científico al quehacer de la disciplina. Sin embargo, esto no es concordante con el análisis epistemológico revisado hasta el momento. El conductismo se da a la tarea de vaciar los enunciados mentalistas (carentes de significado según el conductismo lógico) para traducirlos en estrictos términos comportamentales, y así de este modo, tener un punto de partida libre de errores. Dicho procedimiento es conocido como operacionalización, y pone su fe en que la observación directa de los hechos no puede ser falsa. A esto es lo que Popper llama objetivismo, a la pretensión ingenua de que es posible un punto de partida ver- 
dadero y definitivo, a partir de "...la descripción pura de la conducta” (Popper, 1974, p. 104). Tanto el subjetivismo (como pretensión de un punto de partida cierto á la Descartes), como el objetivismo, serían errores tributarios de una epistemología de sentido común, cuya principal debilidad consistiría en pretender un punto de partida verdadero y cierto para el conocimiento, siendo que "...no hay manera de encontrar un punto de partida con esas características" (Popper, 1974, p. 103).

Para Popper la metáfora de la mente como tabula rasa, y que él llama teoría del cubo (1974) es un empirismo ingenuo que ve en la experiencia la aparición desnuda de los datos, como si éstos fuesen entrando sin más en el cubo de la mente a través de los órganos de los sentidos. Aquí la mente es un cubo (cubeta) porque recibe pasivamente los estímulos del medio en forma directa y ateórica. Para Popper, una observación cualquiera presupone siempre un marco teórico que la hace comprensible, y no es el caso que la observación preceda a la teoría sino más bien lo contrario.

Así entendida la corriente conductista, ella constituye una excepción dentro de las teorías psicológicas no por su pretendida cientificidad sino únicamente porque sus enunciados no están expresados en términos mentalistas. Pero dichos enunciados operacionales proceden de la tesis verificacionista que invoca a la empiria de manera errada, en el sentido de invocarla no para la falsación sino para la verificación. De ahí que el conductismo tampoco satisfaga, a pesar de escapar del subjetivismo, los criterios de cientificidad.

Bajo esta perspectiva podemos rescatar sí en psicología una no despreciable cantidad de informes de investigación empírica, donde las hipótesis son planteadas en formas tales que resultan susceptibles de refutación. Pero es mucho más difícil desmarcar una teoría psicológica que se ofrezca toda ella para ser contrastada categóricamente. Para que una teoría científica sea tal debe exponerse y arriesgar hasta donde pueda su propio pellejo, y esto debe hacerlo a través de la prohibición de los fenómenos, pues mientras más prohibe resultados más se expone a ser falsada.

En este primer examen podríamos decir que la disciplina psicológica tendría al interior de ella misma ciertas zonas o regiones de conocimiento científico, moteadas con otras regiones no científicas, más cercanas al mito. Naturaleza espuria que probablemente sorprende poco a la comunidad psicológica, ya habituada desde temprano a moverse en su condición de híbrido epistemológico.

Mientras tanto nosotros sabemos que para efectos de profesionalidad, dicha distinción de cientificidad poco o casi nada importa a la hora del hacer técnico, pues hasta se mira con cierta complacencia esta pluralidad de rangos epistemológicos, como una fortaleza que le permite al profesional echar mano de una gama extensa y variada de herramientas para intervenir en el mundo práctico de la vida (como el maletín del ferretero), donde los servicios del psicólogo son por suerte aún requeridos.

Ahora bien, si es que al interior de la disciplina la distinción ciencia-no ciencia parece ser un asunto de relevancia menor, no lo es para la imagen externa de ella. Pues el mundo social moderno exige en lo posible cientificidad como fundamento del quehacer técnico, y no una mera tradición artesanal. La imagen social de la psicología ha pretendido siempre acercarse a los cánones estéticos de la cientificidad, arriesgando en ocasiones profundas cirugías cuando el maquillaje epistemológico se ha resquebrajado. Pues cabría la posibilidad de que la disciplina se asumiera sin conflictos en su naturaleza híbrida, también para el resto de los saberes y para el mundo social, y no tan sólo en el reducto privado de tras bambalinas. Sin embargo, este temor a mostrar el rostro genuino proviene también del discurso popperiano. En Popper, pese a que el conocimiento científico deja de ser inductivo y con derecho a leyes, y pese a que la falsación hace de este conocimiento un saber precario y transitorio, la ciencia sigue siendo aún la práctica investigativa que por excelencia nos acerca a la verdad del mundo. Aunque este acercamiento sea gradual y no dado de una vez y para siempre, la ciencia es de entre todas las prácticas sociales que intentan develar y descifrar el mundo, la que más nos acerca a la verdad. De ahí que en seguida de la demarcación lógica de ciencia y no ciencia, venga la valoración implícita de situar lo no científico como un quehacer de rango menor, aunque no despojado de sentido.

La psicología por tanto, tenderá comprensiblemente a ocultar sus rasgos (zonas o regiones de su saber) de no cientificidad frente a la luz pública, como imagen externa, al tiempo que este 


\section{LA PSICOLOGÍA A CONTRALUZ}

ocultamiento no pasará de ser una preocupación meramente 'estética' en acuerdo a la deseabilidad social, toda vez que al interior de la disciplina la disparidad de los estatus científicos en los distintos enfoques psicológicos será motivo no de proscripciones ni extradiciones, sino de esfuerzos conciliatorios, integrativos y eclécti$\cos$.

\section{Sala No 2: Kuhn y la noción de paradigma}

La revisión hecha a propósito de la demarcación popperiana nos es útil ahora para poner a la psicología en un examen de madurez disciplinar. Mientras en Popper encontramos los elementos para revisar si acaso se cumple o no en psicología lo que podríamos llamar la lógica de la investigación científica, en las nociones de Kuhn podemos hallar los elementos para revisar si àcaso la disciplina psicológica puede ser predicada o no como una ciencia suficientemente madura. El Mundo 3 popperiano, donde son inquilinos los productos intelectuales objetivados, alude a la dimensión institucional del conocimiento y los saberes, y es en esta dimensión institucional donde Kuhn sitúa su análisis de la ciencia. Ella es vista como una particular tradición investigativa que se despliega como institucionalidad. Así, las nociones clásicas de Kuhn, más que corresponder a un análisis lógico formal, pueden ser entendidas básicamente como categorías de análisis sociohistórico. En ellas, las ciencias son caracterizadas de acuerdo a los estadios o fases de desarrollo en el que se encuentran, atendiendo por una parte a la presencia o ausencia de un paradigma imperante y compartido al interior de la disciplina, y por otra atendiendo a los cambios estructurales implicados en los relevos de paradigma, una vez que éstos se han constituido como tales.

La noción de paradigma, que luego fuera relanzada como matriz disciplinar por el mismo autor (Kuhn, 1982), en su formulación original alude a una o más realizaciones científicas que son tomadas por una comunidad de científicos en particular, como base y fundamento para su práctica investigativa (Kuhn, 1967). Cuando un paradigma se constituye como tal y entra en acción, la ciencia que se rige por él se aboca a la investigación normal, entendida como el ejercicio de articulación de aquellos fenómenos y teorías que son propuestos por el paradigma. "La ciencia normal consiste en (...) la ampliación del conocimiento de aquellos hechos que el paradigma muestra como particularmente reveladores, aumentando la extensión del acoplamiento entre esos hechos y las predicciones del paradigma y por medio de la articulación ulterior del paradigma mismo" (Kuhn, 1967, p. 52). Esta fase de normalidad constituye la representación más usual que tenemos del progreso científico, pues aquí éste se muestra como acumulación de conocimientos: “...la ciencia normal es la que produce los ladrillos que la investigación científica está continuamente añadiendo al edificio del conocimiento científico" (Kuhn, 1989, p. 56).

Ahora bien, la ecuación conceptual aquí opera de manera tal que la vigencia de un paradigma en una ciencia determinada será condición de normalidad para ella y señal de madurez disciplinar al mismo tiempo. Si bien puede haber investigación científica sin paradigmas, la “....adquisición de un paradigma y del tipo más esotérico de investigación que dicho paradigma permite es un signo de madurez en el desarrollo de cualquier campo científico dado" (Kuhn, 1967, p. 35). Así se habla de ciencia madura toda vez que en ella se reconoce claramente la presencia de un paradigma mayoritariamente compartido por la comunidad científica, y de ciencia no madura cuando en ella aún no podemos reconocer tal condición.

Kuhn distingue en el desarrollo de las ciencias una fase preparadigmática o de inmadurez (una suerte de estadio primitivo), y una fase paradigmática o de madurez, dentro de la cual se suceden fases excepcionales de revolución y crisis de paradigmas. En el primer caso tenemos una pluralidad de teorías y metodologías asociadas, volcadas sobre una no menos variada gama de problemas de investigación. Esto porque al no existir justamente un marco paradigmático, toda pregunta y problema planteado es tan interesante y relevante como cualquier otro (Kuhn, 1967). En el segundo caso, la presencia hegemónica de un paradigma orientador del pensar y del actuar científicos, permite la delimitación de los problemas de investigación en cuanto a su pertinencia y relevancia para con aquella teoría que precisamente se ha erigido en paradigma. No todos los problemas son ya igualmente relevantes ni viables, no todos son pertinentes para esclarecer y recabar información; hay un marco paradigmático que funge como crite- 


\section{VILLALOBOS}

rio y norma de investigación, y frente al cual debe mantenerse la observancia más o menos estricta de la comunidad científica.

Ahora bien, cómo es que una determinada teoría llega a erigirse en paradigma va a depender no tanto de una superioridad absoluta sobre sus competidoras sino de una superioridad relativa y contingente. Esta superioridad se refiere a que dicha teoría se muestra más exitosa en la resolución de aquellos problemas que para la comunidad de científicos en cuestión se han vuelto agudos. "El éxito de un paradigma (...) es al principio, en gran parte, una promesa de éxito discernible en ejemplos seleccionados y todavía incompletos" (Kuhn, 1967, p. 52). Con esto se nos está señalando que las teorías se imponen en ciencia no porque sean más verdaderas, sino porque toman una ventaja instrumental sobre sus competidoras. De esta forma, una ciencia es ciencia propiamente tal cuando en ella podemos distinguir un paradigma en acción. Mientras esto no se observe, hablaremos más bien de un estado precientífico.

Debemos contemplar el hecho de que en Kuhn la distinción ciencia -no ciencia está fuera de un problema de demarcación lógica, y atañe a una categorización descriptiva en términos de cómo se comporta una determinada comunidad de científicos. Así por ejemplo, lo que hace de las ciencias naturales (a diferencia de las sociales) un cuerpo científico maduro no es una u otra definición de su estatus científico, sino el hecho de que dicha comunidad acepta en consenso ciertas realizaciones pasadas como base y fundamento de su quehacer. El estado de inmadurez para las ciencias sociales queda de manifiesto en el hecho de que en ellas se está debatiendo aún si son o no realmente una ciencia. Este es un comportamiento típicamente preparadigmático, y semeja los períodos tempranos o primitivos de aquellos campos que actualmente son reconocidos sin vacilaciones como científicos (Kuhn, 1967). El mismo Kuhn (1967, p. 247) nos señala a manera de ejemplo; "...hay hombres que pretenden que la psicología es una ciencia, debido a que posee tales y cuales características. Otros (...) arguyen que esas características (...) no son suficientes para convertir a ese campo en una ciencia". En estos debates se gastan grandes cantidades de energía sin llegar a delimitar una definición unívoca. La lección que para las ciencias sociales debiera extraerse a partir de las ciencias naturales, es que no se al- canzará la madurez disciplinar cuando se tenga una tal definición de ciencia, sino "...cuando los grupos que actualmente ponen en duda su propio status lleguen a un consenso sobre sus realizaciones pasadas y presentes" (Kuhn, 1967, p. 248), es decir cuando la comunidad de cientistas sociales logre poner en acción un paradigma. Hasta que esto último no ocurra dichas disciplinas estarán condenadas a merodear en las afueras de la ciencia.

A la luz de esta segunda revisión epistemológica y atendiendo a la naturaleza actual de la teorización en psicología pareciera ser que en tanto disciplina la psicología adolece de un estado ¿crónico? de inmadurez científica. En efecto, asistimos en psicología desde los inicios de su pretensión científica ${ }^{2}$, a la presencia múltiple y polivalente de un sinnúmero de corrientes teóricas, enfoques y tradiciones investigativas, que lejos de ir reduciéndose a un número cada vez menor de discursos, han ido en proliferación creciente y divergente, pasando a constituir en la actualidad una constelación varia e inconmensurable de cuerpos teóricos y datos empíricos inarticulados y desmembrados entre sí (por más que el gremio de compiladores y fabricantes de manuales se aventure cada vez más a reservar uno que otro capítulo de integración de los contenidos).

No es difícil constatar dicho estado de cosas cuando vemos que incluso para un mismo fenómeno o concepto psicológico existen múltiples aproximaciones descriptivas, interpretativas y explicativas. Así por ejemplo hablar de aprendizaje, personalidad, motivación, memoria, no se puede hacer sin más y a secas como si toda la comunidad psicológica entendiese en forma unívoca lo que dichos conceptos están refiriendo. En ellos debe quedar siempre explicitado su apellido o lugar de procedencia; motivación según el modelo humanista, según el psicodinámico, según el conductista, según el cognitivo, y así con la mayoría del glosario psicológico tradicional. Por esta razón la enseñanza de la psicología no consiste en señalar qué es lo que se entiende por tal o cual fenómeno, sino en pasar revista a todo lo que se ha dicho (opinado) con respecto a él. En ese sentido y para bienaventuranza de unos y desgracia de otros, la psicolo-

2 Por lo que hemos revisado hasta el momento, la instauración del mítico laboratorio de Wundt allá en 1879 , marcaría más bien el inicio de la pretensión férrea de cientificidad, que el de la cientificidad misma. 


\section{LA PSICOLOGÍA A CONTRALUZ}

gía sigue estando más hermanada con la práctica filosófica, donde el Ser se dice de muchas formas. Y no es el caso que estén separados por una parte la historia de la psicología, con el saber que ella ostenta como tal. Antes bien el saber que ella ostenta se ofrece como un saber histórico (en tanto que panorámico) de los distintos enfoques y modelos teóricos que hoy vemos flotando en el horizonte de cualquier concepto psicológico. Y flotan todos (unos más visibles que otros) justamente porque no ha surgido ni evolucionado ni uno capaz de imponerse categóricamente sobre el resto (hundiéndolos) como para erigirse en paradigma propiamente tal.

Este hecho contrasta típicamente con lo que ocurre en ciencias naturales, donde la educación de los nuevos miembros que se van sumando a las disciplinas prescinde en gran medida de autores o enfoques, y de la exposición histórica de los contenidos. "Después de todo, ¿por qué debiera el estudiante de física leer, por ejemplo, las obras de Newton, Faraday, Einstein o Schrödinger, cuando todo lo que necesita saber sobre esos trabajos se encuentra recapitulado en forma mucho más breve, más precisa y más sistemática en una serie de libros de texto que se encuentran al día?" (Kuhn, 1967, p. 255). Los libros de texto o manuales se encargan en este caso de exponer el marco paradigmático sobre el cual la ciencia en cuestión se apoya. Esta es la forma en que las ciencias naturales ahorran tiempo y energía, dejando estos recursos no para revisar constantemente sus bases, sino para dedicarse a la investigación normal y acumular así conocimiento.

Kuhn (1967) señala que al comparar la naturaleza de la iniciación educativa en las distintas disciplinas humanas, las ciencias sociales (incluida la psicología) quedan a medio camino entre las artes y las ciencias naturales. En efecto, si tomamos a los profesionales del arte veremos que éstos adquieren su instrucción fundamentalmente a partir de la observación y apreciación de las obras de otros artistas. Para ellos los libros de texto sólo tienen un papel secundario, pues difícilmente con el estudio acucioso de manuales de instrucción podrían llegar a constituirse en artistas propiamente tales. En el caso de la historia, sociología, psicología y filosofía, los libros de texto tienen una importancia algo mayor. "Pero incluso en esos campos, los cursos elementales (...) emplean lecturas paralelas en fuentes originales, algunas de ellas de los 'clá- sicos' del campo (...). Como resultado de ello, el estudiante de cualquiera de esas disciplinas está constantemente al tanto de la inmensa variedad de problemas que los miembros de su futuro grupo han tratado de resolver (...), tiene siempre ante él numerosas soluciones, inconmensurables y en competencia, para los mencionados problemas, soluciones que en última instancia tendrá que evaluar por sí mismo" (Kuhn, 1967, p. 254). Nada más cercano al estado actual de la enseñanza en psicología, que deja a los alumnos enfrentados a una pluralidad de discursos y versiones sobre un mismo tópico a veces diametralmente opuestos entre sí, múltiples miradas para un mismo objeto, y múltiples soluciones para un mismo problema. Y nada más cierto también el hecho de que finalmente se les deja a ellos la difícil tarea de decidir qué hacer con toda esa maraña de modelos. La naturaleza preparadigmática de la enseñanza en psicología se viste con una estrategia comunicacional extraída de las proclamas democráticas más progresistas; respeto por la diversidad. Se les inculca a los alumnos de algún modo, generalmente implícito a través del modelamiento que hacen los docentes, el acostumbrarse a la divergencia y respetarla. Norma de conducta valorable si se quiere, pero que oculta la incapacidad de la disciplina para zanjar sus diferencias. El alumno aprende a tolerar las diferencias y termina entendiendo que nadie puede imponerle a nadie su propio discurso, razón por la cual su opción de creerle a uno o más modelos o enfoques va a depender válidamente ya de sus gustos personales, ya de una afinidad con el docente que encarna tal corriente teórica, o simplemente del encantamiento que produzca una fortuita moda intelectual.

Si esta caracterización de la enseñanza psicológica suena más cercana a una descripción de comportamiento político, es que justamente de eso se trata nos dice Kuhn. En estado preparadigmático todo es igualmente valedero e importante, por lo tanto ninguna corriente psicológica podrá arrogarse el derecho a señalar quienes juegan en el juego y quienes no. Todos tienen igual derecho a participar y a presentar su particular punto de vista, nadie se impone sobre el otro, todos tienen el mismo rango. Esta democracia perfecta podría parecer un bello paisaje para un país soñado, pero para una práctica científica dista de ser un ideal de conducta.

En este punto tal vez más de algún lector ya 


\section{VILLALOBOS}

quiere sonreir triunfalmente pensando que sólo bastaría ir un paso más allá de la reflexión kuhninana y situarse a un costado de Feyerabend para rescatar indemne y de manera ejemplar esta anarquía epistemológica que caracteriza al quehacer de la disciplina psicológica. Para desdibujar este supuesto entusiasmo baste decir por el momento que el todo vale feyerabendiano nada tiene que ver con la actitud gremial de protegerse mutuamente las espaldas, palmotearse cortésmente y soslayar sonriendo las profundas diferencias y puntos de discordia. En todo caso y para no salirnos de itinerario, otro ensayo en sí mismo corresponderá a la revisión de la psicología como acción política e ideológica, y su más o menos cuestionable rol ético en la construcción del sujeto contemporáneo.

Otro custodio podrá rumiar sacando cuentas y concluir que la pluralidad de discursos inconmensurables entre sí en psicología corresponde nada más y nada menos que al hecho de que precisamente de eso se tratan las revoluciones científicas señaladas por Kuhn. Como se sabe, "...la característica esencial de las revoluciones científicas es su alteración del conocimiento de la naturaleza intrínseco al lenguaje mismo, y por tanto anterior a todo lo que puede ser completamente descriptible..." (Kuhn, 1989, p. 92), lo que deja naturalmente a los paradigmas vencedores por una parte y a los vencidos por otra, como debe ser en toda revolución, en una incompatibilidad de traducción mutua. Es decir, lo normal en toda ciencia madura sería que los paradigmas que son derrocados se muestren ilegibles a partir de aquellos que los han destituido. Pero esta vez el intento custodio muere casi al momento de nacer, pues para hablar justificadamente de revolución debe preexistir lógicamente un poder susceptible de ser transformado estructuralmente. En el desgobierno acéfalo de lo preparadigmático la inconmensurabilidad de los discursos tiene que ver con la vociferación simultánea de los muchos dialectos tribales, pero en tanto aquí no hay un poder estructurado, no hay un gobierno, en ningún caso puede homologarse esta intraductibilidad a la incompatibilidad lingüística resultante de una revolución científica.

Hemos visto que la modalidad educativa de las ciencias sociales acusaría su condición precientífica al contrastar visiblemente con la enseñanza de las ciencias naturales, en la que los libros de texto constituyen el pilar fundamental y casi exclusivo del traspaso de conocimien- to, obviándose por completo la remisión a fuentes originales. Los alumnos se forman en los primeros años mediante la adquisición del conocimiento acumulado en los paradigmas básicos de la disciplina, conocimientos que están establecidos como tales en términos institucionales y objetivos, es decir, conocimientos que son del dominio público de la comunidad científica y que se'han desprendido ya de la palabra original del autor que los vio nacer.

Desde Kuhn por cierto ya no nos preocupará si encarnamos o no el cuento feliz popperiano de la falsación, o si operamos o no según la lógica de las ciencias, nos preocupará el hecho de estar o no en pié de una institucionalización sólida y ordenada, tal que podamos calificar como una disciplina madura o científica propiamente tal. Pues bien y según parece ser el caso, acá tampoco nos es dable un certificado de aprobación.

\section{Sala $\mathrm{N}^{\circ}$ 3: Maturana y el determinismo estructural}

Una de las voces controvertidas para la psicología ha sido aquella que hoy por hoy ya podríamos llamar la escuela chilena de epistemología. Sabido es que las resonancias de los postulados de Maturana y Varela sobrepasan desde sus inicios el cerco de la medialuna criolla, y que su discurso ha sido adoptado por constructivistas y sistémicos como uno de sus principales desarrollos teóricos, pese a que como es el común de los casos, los autores no se reconocen con comodidad dentro de dichas rotulaciones. Controvertida al menos es la relación que guarda esta epistemología con el corpus psicológico, pues hay los que reciben con entusiasmo el discurso maturaniano, mientras hay los que lo rechazan. Por mi parte puedo presuponer que muchas de estas preferencias y reticencias provienen en buena parte de una inacabada comprensión de las implicancias que para la psicología guarda este enfoque epistemológico, así como de un apresurado examen acerca de las posibilidades técnicas que en él se ofrecen. ${ }^{3}$

\footnotetext{
3 Me inclino a suponer que todo aquél que haya vislumbrado alguna derivación técnica para su psicoterapia, para su práctica educativa, o para cualquier otra área de acción a partir de esta epistemología, verá con buenos ojos a Maturana y Varela. Mientras que por desgracia nos toca saber que el brillo de dichos ojos no proviene de un iluminismo genuino, sino de la visión absorta de quien sólo ve "nuevas áreas de trabajo", o un nuevo discurso para que la psicología se "posicione mejor en el mercado" de las profesiones.
} 


\section{LA PSICOLOGÍA A CONTRALUZ}

A partir de la noción básica de determinismo estructural y siguiendo en estricto sus implicancias tanto para los seres vivos como para el fenómeno del conocer, la epistemología biológica da cuenta simultáneamente de la constitución del observador y de la forma particular en que el ejercicio científico plantea su observar. Es decir, hay aquí no tan sólo una propuesta para entender lo biológico, lo social, el lenguaje y lo mental, sino también una propuesta demarcatoria que señala la lógica particular de la explicación científica.

Probablemente uno de los aspectos menos rescatados por la audiencia sea justamente la demarcación entre ciencia y no ciencia derivada de las nociones maturanianas. En ellas, (Maturana \& Varela, 1984) la explicación científica queda caracterizada como un tipo especial de reformulación lingüística, a saber, aquella que satisface las siguientes condiciones:

a. Descripción del fenómeno a explicar de una manera aceptable para la comunidad de observadores (científicos);

b. proposición de un sistema conceptual capaz de generar el fenómeno a explicar, de una manera aceptable para la comunidad de observadores;

c. deducción a partir de b. de fenómenos adicionales no considerados explícitamente en dicha proposición, así como la descripción de sus condiciones de observación;

d. observación de estos fenómenos deducidos de $b$.

Lo que no está señalado en esta receta es justamente la noción de determinismo estructural, que es precisamente la que otorga la base para rechazar el supuesto de objetividad en ciencia, así como para especificar también qué tipo de unidades son las que pueden ser abordadas por ella. La noción de determinismo estructural implica en primer término, que todo lo que le ocurre y puede ocurrirle a un sistema está determinado en su estructura, en tanto los encuentros que éste tiene o tenga con el entorno sólo operan como perturbaciones que gatillan (pero no especifican) los cambios estructurales acaecidos en él. Ya con aceptar simplemente este principio damos al traste con el supuesto de objetividad reclamado para todo conocimiento y en especial para el conocimiento científico. Si el entorno del sistema nunca entra al sistema porque éste no representa ni configura una imagen de aquél, luego el conocer de dicho sistema tiene que ver con lo puesto por él (su propia estructura y la legalidad de los cambios que puede asumir, así como la selección de los encuentros con el entorno que van a ser tomados como perturbaciones) y no con las características del entorno como tal.

Reemplazando las categorías de sistema/entorno por la matriz más clásica de sujeto/objeto, lo dicho por Maturana y Varela puede dejar sin novedad a los conocedores de la empresa kantiana. Como señala Echeverría (1992) la novedad de estos autores radica más en la procedencia de estas reflexiones que en la reflexión misma. $^{4}$

Si ningún conocimiento puede arrogarse el estatus de objetividad, entonces no caben los distingos entre disciplinas más o menos objetivas. La psicología respira aliviada y celebra el hecho de que ni las ciencias más duras pueden ostentar ya la corona de laureles de la objetividad. Nunca nadie la tuvo, somos todos iguales.

Pero hemos revisado hasta el momento sólo una de las implicancias del determinismo estructural. La segunda implicancia de esta noción es que sólo se puede hacer ciencia con sistemas determinados estructuralmente. De hecho, el criterio de validación científica presupone el determinismo estructural, pues “....sostener que el criterio de validación de una explicación científica está centrado en la proposición de un mecanismo que genera el fenómeno a ser explicado como una consecuencia de su operación, es sostener que la ciencia puede solamente tratar con sistemas determinados estructuralmente" (Maturana, 1992, p. 34). Esto quiere decir que para formular proposiciones generativas debo tener entre las manos un sistema donde puedan distinguirse una organización y estructura particular, es decir, un conjunto de componentes en cierta relación. Allí donde no pueden distinguirse componentes no puedo postular mecanismos generativos, pues simplemente no hay elementos que poner en relación. Sólo cuando hemos definido un sistema como una unidad compuesta podemos preguntar por el origen de sus propiedades, no así en las unidades simples, donde las propiedades pasan a ser características cons-

\footnotetext{
${ }^{4}$ Lo que no quiere decir que la novedad radica en que hay ahora un conocimiento científico de base, pues no es acertado pensar que los filósofos reflexionan de espaldas a la ciencia. La erudición y formación en ciencias del mismo Kant bastaría para desmitificar semejante ingenuidad.
} 
titutivas de la unidad. Bajo esta distinción por ejemplo, el alma entendida como una entidad con carácter ontológico trascendente queda fuera del ámbito científico. Pues "no hay explicación científica para los fenómenos concebidos de partida como propiedades constitutivas de unidades simples. Las condiciones constitutivas no requieren de explicación." (Maturana, 1993, p. 216).

Este mismo argumento es el que conduce al rechazo del discurso mentalista o psíquico como conjunto proposicional válido desde el punto de vista científico para dar cuenta del comportamiento humano y animal. El sistema nervioso como parte de un organismo opera con determinación estructural, esto quiere decir que el cerebro (considerado típicamente como sala de control de los procesos mentales) no representa el mundo. El operar del cerebro no es representacional, lo que significa que ni es referencial ni es intencional en el sentido de Brentano (Priest, 1994). Lo mental no ocurre en el cerebro sino en el espacio relacional de los organismos. "Los entes psíquicos, mentales o espirituales como el yo, el inconsciente, el alma, el espíritu, la conciencia, son entes relacionales (...) que tratamos como si fuesen de la misma clase que los entes materiales manipulables, pero no lo son" (Maturana, 1991, p. 196). Si el rasgo cardinal de lo mental es su intencionalidad (su orden representacional), entonces habrá que buscar su dominio allí donde reina la referencialidad, o sea, en el lenguaje.

Al hacer una descripción de la conducta como surgiendo de los cómputos que el sistema nervioso realiza con representaciones del medio, estamos pasando por alto su determinación estructural y por lo tanto, estamos haciendo una descripción literaria pero en ningún caso científica del comportamiento, por más que dichas nociones de representación se vistan de sofisticada terminología computacional de procesamiento de información. Se replicará entonces que la psicología no trabaja con fenómenos cerebrales sino con fenómenos mentales. Pero he aquí justamente que debemos recordar el criterio de demarcación de la ciencia y preguntarnos si acaso es la mente un sistema con determinación estructural.

Si es la mente una unidad compuesta, y en tanto sistema ella opera con determinación estructural, entonces la psicología así planteada (como estudio de lo mental) es efectivamente una ciencia y sus explicaciones son explicaciones científicas. Por desgracia, lo mental siempre ha requerido para ser tal la noción misma de representación, o sea, la violación flagrante del determinismo estructural, pues aquello que lo diferencia de lo extenso, de la cosa, del orden material, es precisamente su carácter intencional, el ser siempre un acerca de. Y si lo mental es esencialmente representación, entonces lo que ocurre en él no queda determinado en su estructura sino en y por aquello que es representado.

Todas las conceptualizaciones y modelos psicológicos, desde el cógito cartesiano hasta la topografía y composición estructural psicoanalítica, pasando por el cognitivismo y los modelos humanistas, han debido asumir que lo mental (sea metaforizado como aparato, o como software) consiste en un estar abierto al mundo, un captar los datos, un percibir el entorno, en buenas cuentas, un incorporar y procesar información. Todo el discurso mental tiene que por fuerza asumir alguna modalidad representacional, sea que la mente que representa opere como una tabula rasa, como un aparato con apetitos e instintos, como conteniendo leyes de percepción, como un procesador de datos, como un cúmulo de constructos cognitivos, etc. $\mathrm{Y}$ en tanto lo mental para ser tal requiere siempre que un mundo, un algo, un dato, entre en él para ser representado con más o menos distorsiones, opera entonces siempre como un sistema abierto sin determinación estructural.

Ahora bien, dentro de la psicología sólo podemos rescatar un intento serio de superar el mentalismo, y éste es el de la corriente conductista. En efecto, la noción de representación no aparece por ninguna parte cuando la descripción se hace en términos estrictamente conductuales, pues ahí lo mental está cancelado en tanto ficción explicativa. De ahí también la declarada simpatía de Maturana por el trabajo de Skinner, y de ahí la demarcación propuesta para la psicología por el propio Maturana, la cual puede sorprender por su evidente (pero sólo aparente) cercanía a la tradición conductista. Para Maturana la psicología es una rama de la biología en tanto los fenómenos que estudia se dan en el vivir de los seres vivos. Sin embargo se reconoce para ella un dominio propio; el estudio de la conducta. Es decir-tomando el caso con la misma ironía con la que algunos ven en el socialismo simplemente el camino más largo para lle- 


\section{LA PSICOLOGÍA A CONTRALUZ}

gar al capitalismo- podríamos entender al constructivismo como el camino más largo y complicado para llegar al conductismo. Veamos si esto es así.

Cuando Maturana (1993, p. 215) afirma que la psicología posee su propio dominio y que éste es "el estudio de la conducta como la dinámica de las relaciones e interacciones de los animales entre sí y con su medio, en el cual cada animal opera como una totalidad", nos puede incomodar primero que nada el que dicha definición disuelva a la psicología en una suerte de etología, pero más allá de este punto debemos atender al hecho de que el objeto de estudio propuesto para la misma es propiamente el comportamiento, la conducta, y no los procesos mentales.

Hasta aquí, podríamos parear sin más esta definición con la sostenida por el conductismo. No obstante la falacia de emparejar ambos enfoques vendrá dada otra vez por la noción de determinismo estructural. Esta noción implica que los sistemas no reciben estímulos sino que sufren perturbaciones, conceptos que reciben su significado a partir de epistemologías inconmensurables entre sí. Cuando se habla de estímulos se asume un mundo dado, una realidad que influye sobre el organismo modificando la probabilidad de las respuestas futuras. El acento está puesto en la experiencia, pero entendida como el patrón de estímulos del medio que imprimen su fuerza en el organismo y que van moldeando el patrón conductual del mismo. La epistemología es empírica y tributa necesariamente a una ontología realista.

Mientras que al hablar de perturbación se está poniendo el acento en la estructura del organismo como selectora de los encuentros con el medio, y por lo tanto la primacía de un mundo dado que selecciona a través de sus estímulos la conservación o extinción de ciertas conductas, es rechazada. "Skinner no hace ni puede hacer esta distinción porque ella sólo surge de considerar al organismo como un sistema determinado estructuralmente, y él no hace eso" (Maturana, 1993, p. 226).

Tenemos entonces que para la psicología se propone a partir de la epistemología biológica (constructivista radical o de los sistemas cerrados), un dominio de estudio que coincide básicamente con el estudio de la conducta, sólo que teniendo siempre en cuenta que la empiria, como paso necesario dentro del proceder científico, no nos conecta nunca con una realidad objetiva sea por el expediente verificacionista o falsacionista. La ciencia “.... como un dominio de explicaciones y afirmaciones, surge en la praxis de los científicos a través de la aplicación del criterio de validación de explicaciones, (...) y no a través de la aplicación de un criterio de falsación como fue sugerido por Popper" (Maturana, 1992, p. 32). Por lo tanto estudiar la conducta y no los procesos mentales, no convierte a la psicología en un conocimiento objetivo (pues ningún conocimiento puede ostentar dicho rango) sino únicamente en una disciplina científica.

Debe quedar claro que en esta perspectiva el mecanicismo propio de las explicaciones científicas no es visto como reduccionismo, aún cuando lo mental en tanto relación, quede explicado a partir de lo biológico. Cuando se señala que el enfoque es mecanicista y que "...no se aducirán fuerzas ni principios que no se encuentren en el universo físico" (Maturana \& Varela, 1972, p. 12), se está señalando simplemente que lo que interesa al estudiar un sistema no son los componentes ni sus propiedades, “...sino los procesos y relaciones entre procesos, realizados por medio de los componentes" (Maturana \& Varela, 1972, p. 12). El mecanicismo "...no niega la posibilidad de una explicación científica de un fenómeno síquico (...) Por el contrario, abre la posibilidad de explicarlos como un fenómeno biológico" (Maturana, 1992, p. 36).

Bajo esta perspectiva, y dado que la mayor parte de las teorías, enfoques y modelos en psicología hacen uso, aunque de manera varia, del discurso mentalista, no cabría más que desmontar nuestras bibliotecas y comenzar a reescribir bajo un nuevo marco epistemológico, la psicología como ciencia de la conducta. Frente a esta posibilidad la comunidad psicológica se repliega y denuncia entonces al constructivismo radical; “...incorporar el constructivismo radical maturaniano significa importar un Caballo de Troya con un núcleo duro biologicista-conductista que no puede aceptar los estados intencionales de conciencia como reales" (Cornejo, 2001, p. 95).

Mientras que Maturana ve en el mecanicismo propio de las proposiciones generativas la posibilidad de explicación científica para los fenómenos psíquicos, la psicología ve en él la amenaza viva de la reducción biologicista-conductista. 


\section{Conclusión y consideraciones finales}

Si la comunidad psicológica suele incluirse a ella misma dentro de las ciencias, ya sociales, naturales, o como mixtura de ambas, y al mismo tiempo suele estar ausente en ella la reflexión epistemológica y el entendimiento lúcido de todo lo que puede llegar a llamarse científico, el resultado natural de esta curiosa combinación no puede ser si no la de no saber nunca dónde se está parado. Tal condición no debiera ser motivo de celebración claro está, pero tampoco de inmovilidad o ciega defensa. En nada se beneficia el quehacer psicológico con la ignorancia de la discusión epistemológica, pese a que tal discusión tampoco está obligada, ni mucho menos, a darnos buenas noticias. Antes bien, una reacción de intromisión al debate, amparada en el legítimo derecho a voz, valdría como un comportamiento disciplinar mucho más saludable que la actitud pasiva del compás de espera.

El presente ejercicio de examen epistemológico acotado a las nociones de Popper, Kuhn y Maturana, y por tanto ya advertido en su discreta calidad de expedicionario, nos ha mostrado a una psicología que se resiste, positiva o negativamente, a entrar con todas sus letras en el mundo de las ciencias. Como se anticipó, la elección de los autores y sus respectivas conceptualizaciones obedece tan sólo a una suerte de muestreo intencionado, y no a la pretensión de ver en ellos algo así como un tribunal epistemológico de última instancia. Sabemos de sobra que la noción misma de ciencia y la consiguiente ponderación del estatus de las ciencias sociales, e incluso el entendimiento de qué es precisamente hacer epistemología, varía grandemente según las distintas orientaciones y los distintos autores que se han planteado frente al tema. Por la misma razón y para pronunciarnos acerca de la psicología en particular, se han escogido estos tres autores que no siendo reducibles entre sí, y tampoco comportando la muestra representativa del debate epistemológico total, sí que nos conducen por vías independientes a descartar la cientificidad (al menos cabal) de la disciplina psicológica.

La psicología no será una ciencia hasta que el conjunto de teorías que la integran no se ofrezcan verdaderamente a procedimientos de falsación. Bajo la concepción popperiana bien podríamos colegir esta sentencia, que dejaría a la disciplina psicológica actual en evidente es- tado de deuda. La lógica del falsacionismo podríamos asumir, se cumple parcialmente en determinadas zonas de la investigación en psicología, pero no es el caso de la mayor parte de nuestro acervo teórico. La mayor parte de los llamados enfoques psicológicos caen, tomando como criterio esta demarcación, con toda su humanidad dentro del discurso metafísico. Discurso que para Popper ciertamente no está despojado de sentido, pero que debe asumirse sin más en las huestes del mito y la leyenda. Así, y siendo más inteligentes, más nos valdría trabajar en reivindicar lo mítico como un conocer legítimo y no hacer pasar por científico un cuerpo teórico que no lo es. No obstante sabemos también que la sociedad nos encarga ciencia y técnica como base de profesionalidad, y que si de sobrevivir como disciplina se trata, habremos de ir más bien en esta dirección.

Con Maturana obtenemos un diagnóstico similar al que obtuvimos bajo la demarcación popperiana, pero más devastador aún, pues ni siquiera el proyecto falsacionista supone aquí un buen encaminamiento. La operacionalización del glosario psíquico nos deja en posición de conectar empíricamente las hipótesis psicológicas, pero dicha conexión no nos conecta con la certeza ni la verdad. No es la empiria lo que se reclama para las ciencias sino un particular objeto de estudio y un particular criterio de validación; las unidades compuestas como sistemas determinados estructuralmente, y las reformulaciones conceptuales como proposiciones generativas de los fenómenos a explicar, respectivamente. Lo segundo es imposible si no se tiene lo primero, pero lo primero no es suficiente para adjudicar cientificidad, pues el sentido común prácticamente en toda latitud suele tratar la mayoría de los fenómenos como expresión de sistemas determinados estructuralmente (aunque no esté al tanto de que lo está haciendo). Para Maturana no hay en rigor entonces psicología escrita en formato científico, salvo aquella que se ha volcado estrictamente sobre la conducta. Pero esta última tampoco califica como ciencia pues por su afán la conoceréis. El énfasis en el control, predicción y manipulación de la conducta sitúa al conductismo más en el ámbito de la tecnología que en el de la ciencia. Pues "tecnología y ciencia requieren de emociones distintas: pasión explicativa en el hacer ciencia, y pasión productiva o pasión de control en el hacer tecnología" (Maturana, 1993, p. 228). 


\section{LA PSICOLOGÍA A CONTRALUZ}

Parece ser sin embargo que si hay algo de lo cual se precia la psicología -si hay algo a lo que puesta a elegir no renunciaría- es al hecho de ser una disciplina capaz de ofrecer tecnología de la conducta y de la psique, más que al hecho de ofrecer un conocimiento científico de las mismas. Pasión productiva versus pasión reflexiva. La autopredicación de cientificidad en psicología vendría jalonada y a la siga, de una más importante y solícita oferta de saberes técnicos.

Sabemos que en su vertiente investigativa, digamos cuando profesa cientificidad, la psicología se ofrece como la pregunta sistemática acerca del comportamiento humano y sus determinantes, utilizando como método interrogativo estudios experimentales, cuasi experimentales y no experimentales, metodologías cuantitativas y cualitativas, aproximaciones correlacionales y clínicas, análisis de datos, etc. En su vertiente técnica la psicología se ofrece como profesión, como experticia técnica en el diagnóstico, prevención, y tratamiento de trastornos y desajustes psíquico conductuales, experticia técnica en el manejo y desarrollo de los recursos humanos dentro de las organizaciones, experticia técnica en la evaluación y diseño de programas educacionales, y experticia técnica en el diagnóstico de factores de riesgo social e implementación y diseño de intervenciones comunitarias,

Cuál será el rango que se le otorgue a su cientificidad y desarrollo técnico dependerá del punto de referencia que se tome para evaluarla; visto desde las ciencias duras la psicología no pasaría de ser un intento frustrado de cientificidad, y desde las disciplinas ingenieriles las técnicas psicológicas calificarían como juego de niños (lo cual no implica que sean inofensivas sino todo lo contrario). Pero visto desde el lego o eventual usuario común, la psicología tomaría cada vez más un semblante de cientificidad y desarrollo técnico, que le otorgarían el rango de profesión más que de ciencia.

En efecto, para el común de la gente tal vez no quede claro si al hablar de psicología se está hablando de una ciencia estricta, pero sí queda claro que si la persona que se tiene en frente es un psicólogo, entonces se está frente a un profesional, y no a un aficionado. En ese sentido, para la población común y corriente, esto es, para el consumidor promedio, la psicología ofrece una cierta garantía de experticia técnica suficiente como para pagar por sus servicios, más allá de si tal experticia está fundada o no en un saber rigurosamente científico. De ahí probablemente la poca inclinación de la disciplina a hacerse cargo del debate epistemológico, y digo hacerse cargo para diferenciar esta actitud de otra muy distinta que es la de enterarse del debate. Podríamos admitir que la comunidad psicológica está enterada de los avatares en epistemología, que no camina de espalda a ellos, pero podríamos asumir también y con razón que este enterarse viene dado casi exclusivamente por la posibilidad de derivación y utilización técnica que en ellos se ve brillar. Dicho en otros términos, el debate epistemológico suele llegar a la psicología ya mediado por la mera utilización técnica.

Y podríamos presumir también que dicha mediación técnica condiciona en buena parte la naturaleza de la enseñanza y formación de los psicólogos. Cuando a propósito de la caracterización que hace Kuhn de cómo se refleja el estatus de cientificidad en la enseñanza de las disciplinas, vemos que la psicología efectivamente cae en ese terreno intermedio entre el arte y la ciencia, no debiéramos complacernos fácilmente con la retórica de que somos ambas cosas. Nadie ha dicho que estar a medio camino entre dos géneros sea equivalente a la síntesis virtuosa que tiene lo mejor de cada cual. En todo caso, si alguien quisiera ver en la psicología la feliz comunión entre arte y ciencia, se decepcionaría por una parte con una literatura extremadamente concreta y poco imaginativa, y chocaría por otra con un desorden de saberes preparadigmáticos propios de lo precientífico. ${ }^{5}$

La condición de híbrido debiera ser pasto de problematización y espíritu crítico, y no de condescendencia. Y sin embargo, veremos que la mayor parte de las veces la iniciación de los psicólogos consistirá básicamente en un paseo por los distintos y supernumerarios enfoques y modelos, para pasar prontamente, previa elección a gusto personal, a la adquisición de las herramientas técnicas en uso actual, sin que se hayan acusado las inconsistencias ni hayan sido advertidos suficientemente los vacíos epistemológicos. Bajo esta lógica claro está, ni se justifica ni puede ser visible la necesariedad de pensar nuestra epistemología. Después de todo ¿para qué perder el tiempo en humaredas de cerebro

5 Mucho más boquiabierto si entiende por síntesis artístico científica la reflexión propia de la filosofía; allí no encontrará más que deslavadas versiones y pseudofilosofías de bolsillo. 


\section{VILLALOBOS}

si el saber técnico funciona y -como diríamos en jerga televisiva- la gente lo pide?

Frente a este panorama la tarea que nos toca, al menos así se intuye, es la de hacer de lo psicológico no sólo un ámbito del saber, sino también y sobre todo un ámbito del conocer, del preguntar y del comprender.

\section{Referencias}

Cornejo, C. (2001) Piaget, Vigotski y Maturana: Tres Voces, Dos Constructivismos. Psykhe, 10, (2), 87-96.

Echeverría, R. (1991) El búho de Minerva. Chile: Dolmen. Kuhn, T. (1971) La estructura de las revoluciones científicas. México: Fondo de Cultura Económica.

Kuhn, T. (1982) La tensión esencial: Estudios selectos sobre la tradición y el cambio en el ámbito de la ciencia. México: Fondo de Cultura Económica.
Kuhn, T. (1989) ¿Qué son las revoluciones científicas? Y otros ensayos. Barcelona: Paidós.

Maturana, H. (1991) El sentido de lo humano. Santiago: Dolmen.

Maturana, H. (1992) La objetividad: Un argumento para obligar. Santiago: Dolmen.

Maturana, H. (1993). Desde la biología a la psicología. Viña del Mar: Editorial Synthesis.

Maturana, H., \& Varela, F. (1970) De máquinas y seres vivos. Autopoiesis: La organización de lo vivo. Santiago: Editorial Universitaria.

Maturana, H., \& Varela, F. (1984). El árbol del conocimiento: Las bases biológicas del entendimiento humano. Santiago: Editorial Universitaria.

Popper, K. (1962) La lógica de la investigación científica. Madrid: Tecnos.

Popper, K. (1967) Conjeturas y refutaciones: El desarrollo del conocimiento científico. Barcelona: Paidós.

Popper, K. (1974) Conocimiento objetivo. Madrid: Tecnos.

Priest, S. (1994) Teorías y filosofías de la mente. Madrid: Cátedra. 